AIAA-2001-2277

\title{
STRUCTURAL AND ACOUSTIC NUMERICAL MODELING OF A CURVED COMPOSITE HONEYCOMB PANEL
}

\author{
Ferdinand W. Grosveld* \\ Lockheed Martin Engineering and Sciences \\ Hampton, VA 23681 \\ Ralph D. Buehrle ${ }^{\dagger}$ and Jay H. Robinson ${ }^{\ddagger}$ \\ NASA Langley Research Center \\ Hampton, VA 23681
}

\begin{abstract}
The finite and boundary element modeling of the curved section of a composite honeycomb aircraft fuselage sidewall was validated for both structural response and acoustic radiation. The curved panel was modeled in the pre-processor MSC/PATRAN. Geometry models of the curved panel were constructed based on the physical dimensions of the test article. Material properties were obtained from the panel manufacturer. Finite element models were developed to predict the modal parameters for free and supported panel boundary conditions up to a frequency of $600 \mathrm{~Hz}$. Free boundary conditions were simulated by providing soft foam support under the four corners of the panel or by suspending the panel from elastic bands. Supported boundary conditions were obtained by clamping the panel between plastic tubing seated in grooves along the perimeter of a stiff and heavy frame. The frame was installed in the transmission loss window of the Structural Acoustic Loads and Transmission (SALT) facility at NASA Langley Research Center. The structural response of the curved panel due to point force excitation was predicted using MSC/NASTRAN and the radiated sound was computed with COMET/Acoustics. The predictions were compared with the results from experimental modal surveys and forced response tests

\footnotetext{
Aerospace Engineering Manager, Associate Fellow

tAerospace Engineer, Structural Acoustics Branch

${ }^{\ddagger}$ Aerospace Engineer, Structural Acoustics Branch

Copyright @ 2001 by the American Institute of Aeronautics and Astronautics, Inc. No copyright is asserted in the United States under Title 17, U.S. Code. The U.S. Government has a royalty-free license to exercise all rights under the copyright claimed herein for Govermment Purposes. All rights are reserved by the copyright
} owner.
\end{abstract}

on the fuselage panel. The finite element models were refined and updated to provide optimum comparison with the measured modal data. Excellent agreement was obtained between the numerical and experimental modal data for the free as well as for the supported boundary conditions. Frequency response functions (FRF) were computed relating the input force excitation at one panel location to the surface acceleration response at five panel locations. Frequency response functions were measured at the same locations on the test specimen and were compared with the calculated FRF values. Good agreement was obtained for the real and imaginary parts of the transfer functions when modal participation was allowed up to $3000 \mathrm{~Hz}$. The validated finite element model was used to predict the surface velocities due to the point force excitation. Good agreement was obtained between the spatial characteristics of the predicted and measured surface velocities. The measured velocity data were input into the acoustic boundary element code to compute the sound radiated by the panel. The predicted sound pressure levels in the far-field of the panel agreed well with the sound pressure levels measured at the same location.

\section{INTRODUCTION}

NASA Langley Research Center has agency responsibility for aircraft interior noise control in both subsonic and supersonic aircraft. Numerical computational schemes and structural optimization techniques are being employed to model, predict, validate and minimize aircraft interior noise. ${ }^{1.9}$ Design technologies are being developed to provide significant interior/payload bay noise reduction with 
minimal weight penalty. The goal is to integrate the noise source definition, the structural acoustics prediction and the noise control technologies in the early stages of the design process allowing the structural parameters to be optimized for passive and active noise control. High fidelity, manageable numerical models of built-up aerospace structures are being created based on the geometric, structural and material properties of the participating components. The transmission loss characteristics of several aluminum and honeycomb composite curved panels with integral damping were previously measured in the Transmission Loss Apparatus at NASA Langley Research Center. ${ }^{10-11}$ However, finite and boundary element models are needed to predict the sound transmission properties in the preliminary design phase. In the current study, finite element (FE) and boundary element (BE) analyses were applied to a curved section of a composite honeycomb aircraft fuselage sidewall. The test panel was modeled in the pre-processor MSC/PATRAN. The structural responses of the curved panel were predicted using MSC/NASTRAN and the radiated sound due to a point force excitation was computed with COMET/Acoustics. The numerical predictions for modal frequencies and mode shapes were verified with the results from experimental modal surveys up to a frequency of $600 \mathrm{~Hz}$. The finite element models were refined and updated to provide optimal comparison with the measured data. Frequency response functions (FRF) between force input and acceleration response were measured at several locations on the test specimen and compared with the calculated FRF values. The particle velocities at the finite element defined nodal points of the curved panel were computed and compared with the velocities measured by a laser vibrometer. The measured velocity data was input into the boundary element model to calculate the acoustic responses in the far field. The predictions from the acoustic boundary element method were verified by comparing the results with the measured far-field radiated sound. The paper describes the procedures, discusses the analyses, summarizes the results and presents the conclusions.

\section{CURVED COMPOSITE HONEYCOMB PANEL}

A section of a curved fuselage panel was made available by the manufacturer to perform vibroacoustic testing. The fuselage panel was made of a flexible honeycomb core sandwiched between two composite laminates. The panel was used as a test article for experimental verification of the predictions made with numerical finite element and boundary element models. Experimental modal surveys were conducted for free and supported boundary conditions. Free edge conditions were accomplished by placing the four corners of the panel on soft foam or by suspending the panel from elastic bands. Supported boundary conditions were obtained by clamping the top and bottom edges of the panel between plastic tubing embedded in a stiff wooden frame. The supporting frame was bolted to the 55.5 by 55.5 inch transmission loss window in the Structural Acoustic Loads and Transmission (SALT) facility $^{12}$ at NASA Langley Research Center. A photograph of the curved composite honeycomb panel installed in the SALT facility is shown in Figure 1. The walls of the supporting frame consisted of two inch thick medium-density fiberboard to provide adequate noise transmission loss and prevent flanking paths.

\section{STRUCTURAL FINITE ELEMENT MODEL}

A right-handed Cartesian coordinate system was chosen for the global FE space. A local, righthanded cylindrical coordinate system $(R, T, Z)$ was selected for the geometry and the finite element definition of the curved panel. The origin of the local coordinate system was positioned at the center of the circle segment defining the panel curvature. The Z-direction was chosen along the centerline of the curved panel. The panel was meshed with 42 elements along the curvature and 42 elements along the straight edge. The composite outer and inner laminates were represented by 1764 CQUAD4 plate elements having 2D-orthotropic material characteristics and PCOMP element properties (Table 1). The honeycomb core consisted of 1764 CHEXA six-sided solid elements with 3D-orthotropic material properties and PSOLID element properties. Coincident nodes of the substructures were equivalenced to remove redundant nodes at the junction points. Figure 2 shows a quad view of the curved panel finite element model. The total degrees of freedom (DOF) for the equivalenced structure were estimated at 21,168. The curved composite panel consisted of two 0.0305 -inch thick composite laminates bonded to the inside and outside of a 0.777 -inch thick honeycomb core by a 0.002 -inch thick film adhesive. The total 0.838 -inch thickness of the core and the composite inner and outer 
laminates was reduced to 0.820 inches during the curing process. The composite panel had a curvature radius of 41.46 inches, measured from the origin of the cylindrical coordinate system to the center of the panel thickness. The panel sector angle measured 85.8 degrees resulting in an arc length of 62.08 inches along the centerline of the curvature thickness. The straight edge width of the panel was 54.78 inches. The panel surface area covered 3401 square inches. The weight of the test panel was measured at $19.29 \mathrm{lbs}$. The total weight of the components in the finite element model equaled 19.66 lbs. The $1.9 \%$ higher mass used in the finite element model would lower the predicted modal frequencies by less than $1 \%$, which was considered not to be significant in this study. The panel geometry and weight properties for the test article and numerical model are summarized in Table 2.

\section{MODAL ANALYSIS}

A normal mode analysis of the curved honeycomb composite panel was performed in MSC/NASTRAN for frequencies up to $600 \mathrm{~Hz}$ using Solution 103. The modal data were analyzed in the post-processor MSC/PATRAN to obtain the structural mode shapes and mode numbers. Modal frequencies were predicted for free and supported boundary conditions and compared with the results of experimental modal surveys on the curved composite panel.

\section{Free Boundary Conditions.}

Thirty-three modes below $600 \mathrm{~Hz}$ were predicted for the panel with free boundary conditions around the perimeter edges. The free edge boundary conditions were achieved by resting the panel on soft foam supports or by suspending the panel from elastic bands. The mode shapes were identified by the number of nodal lines (i) parallel to the straight edge of the panel and the number of nodal lines following the curvature of the panel (j). The mode shapes and the modal frequencies predicted for the free edge conditions (foam support) are listed in Table 3. Two arbitrarily chosen mode shapes, $(2,0)$ and $(3,1)$, are pictured in Figure 3 for the free boundary conditions. Experimental modal surveys were performed with a piezo-electric equipped force cell hammer and several accelerometers bonded to the surface of the panel. Sixteen experimental modal frequencies were extracted from the averaged transfer functions for the free boundary conditions. The comparison between the modal frequencies predicted by the finite element calculations and the modal frequencies extracted from the experimental modal survey are summarized in Table 3. Excellent agreement, within $2.6 \%$ error, was obtained for the panel resting on soft foam supports. Agreement within $1.5 \%$ error was obtained with the test panel suspended by elastic bands except for the $(1,1)$ and $(2,1)$ modes which were $7.3 \%$ and $3.8 \%$ out of agreement. A graphical comparison between predicted modal frequencies and measured modal frequencies for the elastic support is depicted in Figure 4. Experimental modal frequencies above 100 $\mathrm{Hz}$ were virtually the same for either of the two free edge boundary simulations. The three experimental modal frequencies below $100 \mathrm{~Hz}$ were found lower for the test article suspended by the elastic support. The modal damping was practically the same for either of the free boundary simulations with some variation in the damping at the lowest modal frequencies. The honeycomb core was also modeled with eight stacked solid elements to determine if the stress variation through the thickness was accurately captured. The modal frequencies predicted for the eight-layer solid element honeycomb core model were within $0.1 \mathrm{~Hz}$ of the modal frequencies predicted for the one-layer model. It was concluded that the one-layer core model adequately captured the stress distribution across the honeycomb thickness.

\section{Supported Boundary Conditions.}

Supported boundary conditions were accomplished by installing the curved composite panel in a stiff, heavy wooden frame. The straight and curved edges of the test panel were held on both sides by plastic tubing along the panel perimeter. The tubing was seated in grooves that were routed into the wooden frame. This edge support design was chosen to obtain evenly distributed boundary conditions along the panel perimeter and to provide a reasonably tight acoustic seal. Finite element modal analyses were performed for simply supported, clamped and grounded springs boundary conditions of the curved panel. Eleven modal frequencies below $600 \mathrm{~Hz}$ were identified by an experimental normal mode survey. The experimentally obtained modal frequencies were compared with fifteen predicted modal frequencies for simply supported and clamped edge conditions. The simply supported and clamped normal mode predictions were within $0.8 \%$, which was closer than expected and most likely due to the stiffness provided by the curvature of the panel. A curved panel is stiffer than a flat panel with the same material 
properties. Changing from simply supported to clamped boundary conditions therefore adds less stiffness to a panel that is curved than it would add to a flat panel. Associated modal frequencies for a curved panel will thus shift less in frequency than the modal frequencies for a flat panel. Two predicted mode shapes of the curved simply supported panel, $(2,0)$ and $(3,1)$, are depicted in Figure 5. The predicted mode shapes were used for comparison with the measured mode shapes. The experimental and predicted modal frequencies differed substantially for both the simply supported and the clamped boundary conditions. The predicted $(1,0)$ panel mode for both boundary conditions was more than twice the experimentally obtained $(1,0)$ panel mode. The other predicted and measured panel modes differed between $-12.7 \%$ and $23.8 \%$. To obtain better agreement with the measured modal frequencies, the boundary conditions in the FE model were simulated by grounded springs suspended from all the nodes along the perimeter of the panel. The grounded springs were modeled with the scalar spring connection CELAS1 bulk data entry in MSC/NASTRAN. Seven different elastic property values were considered (PELAS bulk data entry), arbitrarily starting at 7 with each consecutive value increasing ten-fold up to $7,000,000$. The grounded springs were the only constraints imposed on the perimeter nodes and were aligned with the global $x$ axis. The modal frequencies predicted for this FE model are displayed in Figure 6 for the seven elastic property values. The predicted modal frequencies were compared with the modal frequencies extracted from the experimental modal analysis with the test panel installed in the SALT transmission loss window. Twelve experimental modal frequencies were identified below $600 \mathrm{~Hz}$ and are tabulated in Table 4. The twelve measured modes were in excellent agreement (less than $3.1 \%$ difference) with the predicted frequencies for the panel with the grounded springs having an elastic property value of 7,000,000. Twenty-one modal frequencies were predicted below $600 \mathrm{~Hz}$. Two predicted mode shapes for the supported boundary conditions, $(2,0)$ and $(3,1)$, are depicted in Figure 7 . A graphical comparison between the predicted and measured modal frequencies for the supported boundary conditions is presented in Figure 8, showing good agreement. The grounded springs were chosen in the $\mathrm{x}$-direction, almost in line with the in-plane stresses along the panel curvature. These boundary conditions were selected for subsequent structural and acoustic analyses. Grounded springs with an elastic property value of $7,000,000$ were also modeled in the $y^{-}$and $z$-directions but, as expected, substantial deviations from the measured modal frequencies were obtained.

\section{TRANSFER FUNCTIONS}

\section{Input and response locations}

Frequency response functions of the test specimen were measured simultaneously between the force input from a mechanical shaker and the accelerometer outputs at five locations on the panel. The force input location (which was also an accelerometer location) and accelerometer response locations $1-4$ are indicated in Figure 9 along with the center of the panel. These input and response locations were chosen such that they would not coincide with the nodal lines of most mode shapes to ensure a measurable output over a wide range of frequencies. The predicted modal analysis results were used to establish the nodal lines for the twenty-one mode shapes below $600 \mathrm{~Hz}$. The input and response locations are superimposed on two predicted mode shapes, $(2,0)$ and $(3,1)$, in Figure 10 . For most of the mode shapes, the input and at least two or three response locations were away from the nodal lines yielding measurements well above the noise floor. However, the input and/or response location for some modes, like the $(2,0)$ and $(3,0)$ modes in Figure 10 , were very close to a nodal line and the corresponding transfer functions had a poor response at those frequencies. The mode shape patterns of two measured modes are depicted in Figure 11. The measured mode shapes are not as symmetric as the predicted mode shapes due to slight variations in boundary conditions, in-plane panel stresses, amount of curvature, material properties, etc.

\section{Measured and predicted transfer functions}

The experimental frequency response functions serve to validate the response functions predicted by the finite element method for the same locations. The real part of the measured transfer function between the driving point force and the acceleration response at the same location is plotted in Figure 12 for frequencies between $100 \mathrm{~Hz}$ and $600 \mathrm{~Hz}$. Also plotted in Figure 12 is the predicted real part of the transfer function using a modal superposition approach (Solution 111), including all modes up to $600 \mathrm{~Hz}$. Modes above $600 \mathrm{~Hz}$, however, also 
contribute to the modal response below that frequency. Since these modal contributions were not included in the prediction, the comparison with the measured data shows a discrepancy that increases with frequency (Figure 12). The predicted imaginary part of the transfer function showed a similar trend when compared with the measured results from the modal survey. By truncating these higher modes the number of degrees of freedom is reduced. The coupling between the reduced set of modes is also eliminated if only modal damping is used. This modal approach is less computationally intensive than the direct approach but also deviates more from the actual results as the frequency gets higher. In the direct approach (Solution 108) the dynamic equations are solved in their original form which requires longer computing times but yields more accurate results. The real part of the transfer function, numerically calculated using the direct approach, is compared with the experimental results for a frequency-independent critical damping ratio of $1 \%$ in Figure 13. The comparison between the predicted and measured average trend is much better than for the modal approach where only modes up to $600 \mathrm{~Hz}$ were participating. However, the critical damping ratio of $1 \%$ for the predicted transfer function is lower than measured by the modal surveys resulting in many sharp peaks and valleys in the transfer functions. The lowest measured modal critical damping ratios are about $1.75 \%$ (Table 4 ). The predicted transfer function with the $1.75 \%$ critical damping is compared with the measured transfer function in Figure 14. Agreement was improved using the higher critical damping values. The predicted response around the $140 \mathrm{~Hz}$ frequency (Figures 13 and 14) is more pronounced than the measured response within that frequency band. Two modes were predicted in that frequency region, the $(1,0)$ at $138.6 \mathrm{~Hz}$ and the $(0,0)$ mode at $142.6 \mathrm{~Hz}$. However, only one mode, the $(1,0)$ mode at $142.0 \mathrm{~Hz}$ (Table 4), was extracted from the measurements by the modal curve fitter. The $(0,0)$ mode is close to the measured $(1,0)$ mode and might have blended in with the $(1,0)$ mode since the $(0,0)$ mode does not have any nodal lines. Good comparisons between predicted and measured transfer functions, for the real as well as the imaginary part, were also obtained using the direct approach for the other accelerometer response locations and the point force excitation. The element structural damping coefficient in MSC/NASTRAN is handled by a material property definition and as such is independent of frequency. A more accurate damping model was obtained by using the modal approach and including the frequencydependent measured modal damping as a table in the bulk data file. The predictions of the transfer functions below $600 \mathrm{~Hz}$ using the modal approach were further improved by including the contributions from higher modes. Transfer function predictions below $600 \mathrm{~Hz}$ were made while including modes up to an arbitrarily chosen upper limit frequency of 3000 $\mathrm{Hz}$. Modes at frequencies higher than $3000 \mathrm{~Hz}$ were considered unlikely to contribute significantly to the frequency response below $600 \mathrm{~Hz}$. The measured modal critical damping values from Table 4 were used for modes below $600 \mathrm{~Hz}$. For the modes between $600 \mathrm{~Hz}$ and $3000 \mathrm{~Hz}$ the modal critical damping ratio was not measured but estimated at $2 \%$. Good agreement was obtained between the predicted and measured real parts of the transfer function for the driving force and the response at that location (Figure 15). Real and imaginary parts of the predicted and measured parts of the transfer functions between the driving force and the other accelerometer locations were found to compare equally well. Transfer function predictions below $600 \mathrm{~Hz}$ by the direct approach and by the modal approach including contributions from modes up to $3000 \mathrm{~Hz}$ can be compared in Figures 14 and 15. The predicted real part of the transfer function using the modal approach was closer to the measured data. The predictions using the direct method took 25745 seconds of user time to complete on a DEC Alpha machine running Digital Alpha UNIX V4.0. The modal approach predictions (modal participation up to $3000 \mathrm{~Hz}$ ) was completed in 11581 seconds, less than half the user time on the same machine. Just for comparison, the inaccurate modal approach predictions with modal participation up to $600 \mathrm{~Hz}$ took only 1273 seconds of user time to complete.

\section{ACOUSTIC BOUNDARY ELEMENT MODEL}

After the successful validation of the transfer function computations, the particle velocities over the panel surface were predicted using the modal approach including modes up to $3000 \mathrm{~Hz}$. Damping values for the analysis were based on the measured modal damping in Table 4 and $2 \%$ critical damping above $600 \mathrm{~Hz}$. The excitation force was applied at a location on the outside curvature of the panel facing the reverberation room of the SALT facility. The surface velocities were predicted and measured over the surface on the inside of the panel curvature facing the anechoic chamber of the SALT facility. The 
surface velocities were numerically calculated in MSC/NASTRAN for four hundred frequencies between $100 \mathrm{~Hz}$ and $600 \mathrm{~Hz}$. The predicted surface particle velocities were input into a boundary element model of the curved composite honeycomb panel using COMET/Acoustics. The FE model consisted of a 42 by 42 grid with a total of 1764 elements. The BE model, however, was meshed with 256 elements. An interpolation scheme was used to map the FEpredicted surface velocities onto the $\mathrm{BE}$ mesh. Figure 16 shows the predicted surface velocities for a frequency of $202.5 \mathrm{~Hz}$. This frequency was selected since it is between the predicted frequency of the $(2,0)$ mode at $205.6 \mathrm{~Hz}$ (Figure 10) and the measured frequency of that mode at $201.2 \mathrm{~Hz}$ (Figure II). The $(2,0)$ mode has two nodal lines parallel to the panel straight edge. A dominant sound pressure level peak was found for this mode in the acoustic far field. A scanning laser doppler vibrometer was used to measure the surface velocity at each of the boundary element nodes due to a pseudo random shaker input. The measured velocity data was interpolated and mapped onto the BE mesh as shown in Figure 17. The spatial characteristics for the measured and predicted (Figure 16) surface velocities at $202.5 \mathrm{~Hz}$ were in good agreement. In the BE method only the boundary at the panel surface needs to be discretized to solve for the sound radiation from the panel. The sound pressure was computed from the measured surface velocities using the direct $B E$ modeling approach. The sound pressure levels (SPL) in the far field were predicted at a distance of 3.7 meters from the panel center. The predictions from the acoustic $B E$ method were verified by comparing the predicted sound pressure levels with the far-field radiated sound pressure levels measured by a microphone at the same location. Figure 18 shows that good agreement was obtained between the measured and predicted farfield sound pressure levels.

\section{SUMMARY}

A section of a curved aircraft fuselage panel was made available by the manufacturer to perform vibroacoustic testing and conduct a verification analysis. A normal mode analysis was performed in MSCINASTRAN. The modal data were analyzed and post-processed in MSC/PATRAN. The finite element models were refined and updated to provide optimum comparison with the measured data. Experimental modal surveys were conducted for free and supported boundary conditions. Excellent agreement, within $2.6 \%$ error, was obtained between the numerically predicted and measured modes for the panel supported on soft foam blocks. Very good agreement within $1.5 \%$ error (except for the 1,1 and 2,1 modes which were $7.3 \%$ and $3.8 \%$ out of agreement) was obtained for the case where the panel was suspended from elastic bands. Supported boundary conditions were provided by clamping the panel between plastic tubing seated in grooves around the perimeter of a heavy and stiff frame. The frame was installed in the transmission loss window of the Structural Acoustic Loads and Transmission (SALT) facility at NASA Langley Research Center. The finite element predictions were compared with the results from experimental modal surveys on the test specimen resulting in excellent agreement between the numerical and experimental modal data for the supported boundary conditions. Frequency response functions (FRF) were computed relating the input force excitation at one location on the panel to the surface acceleration response at five locations. Frequency response functions between the force input and acceleration response were measured at the same locations on the test specimen and compared with the calculated FRF values. Good agreement was obtained for the real and imaginary parts of the transfer functions using the direct approach with frequency-independent damping. The modal approach yielded better agreement when allowing modal participation up to $3000 \mathrm{~Hz}$ and including measured modal damping input. The modal damping above $600 \mathrm{~Hz}$, which was not measured, was assumed constant and equal to the average damping values of the modes close to the $600 \mathrm{~Hz}$ upper limit. The validated finite element model was used to predict the surface velocities due to the point force excitation. Good spatial agreement was obtained between the predicted and measured surface velocities at 202.5 $\mathrm{Hz}$. The measured velocity data was input into the $\mathrm{BE}$ code to compute the far-field noise radiated by the panel for frequencies between $100 \mathrm{~Hz}$ and 600 Hz. The predicted sound pressure levels in the farfield, at a distance of 3.7 meter on the centerline of the panel, agreed well with the sound pressure levels measured at the same location.

\section{ACKNOWLEDGEMENT}

This work was supported by NASA Langley Research Center, (NAS1-00135) PBC, Dr. Richard J. Silcox, Technical Monitor. The FE and BE data conversion support by Jake Klos is gratefully acknowledged. 


\section{REFERENCES}

1. Grosveld, F. W., "Numerical Comparison of Active Acoustic and Structural Noise Control in a Stiffened Double Wall Cylinder," AIAA Paper 96-1722, 2nd AIAA/CEAS Aeroacoustics Conference, State College, PA, May 6-8, 1996.

2. Fernholtz, C. and Robinson, J. H., "An Investigation of the Influence of Composite Lamination Angle on the Interior Noise Levels of a Beech Starship," INCE Proceedings of Noise-Con 96, Bellevue, WA, September 29 October 2, 1996.

3. Cunefare, K., Crane, S., Engelstad, S. and Powell, E., "A Tool for Design Minimization of Aircraft Interior Noise," AIAA Paper 96-1702, 2nd AIAA/CEAS Aeroacoustics Conference, State College, PA, May 6-8, 1996.

4. Grosveld, Ferdinand W., "Structural Normal Mode Analysis of the Aluminum Testbed Cylinder (ATC)," AIAA Paper 98-1949, 39th AIAA/ASME/ASCE Structures, Structural Dynamics, and Materials Conference, Long Beach, California, April 20-23, 1998.

5. Fleming, G. A., Buehrle, R. D., and Storaasli, O.L., "Modal Analysis of an Aircraft fuselage Panel Using Experimental and Finite-Element Techniques," Proceedings of the $3^{\text {nd }}$ International Conference on Vibration Measurements by Laser Techniques, Ancona, Italy, June 1998.

6. Pappa, R. S., Pritchard, J. L., and Buehrle, R. D., "Vibro-Acoustics Modal Testing at NASA Langley Research Center," NASA/TM 1999209319 , May 1999.

7. Buehrle, Ralph D., Grosveld, Ferdinand W., Pappa, Richard S., and Fleming, Gary A., "Finite Element Model Development and Validation for Aircraft Fuselage Structures," IMAC-XVIII Conference on Structural Dynamics, San Antonio, Texas, February 7-10, 2000.

8. Buehrle, Ralph D., Fleming, Gary A., Pappa, Richard S., and Grosveld, Ferdinand W., "Finite Element Model Development for Aircraft Fuselage Structures," Sound and Vibration Magazine, January 2001.
9. Buehrle, Ralph D., Robinson, Jay H. and Grosveld, Ferdinand W., "Vibro-Acoustic Model Validation for a Curved Honeycomb Composite Panel," AIAA Paper 2001-1587, 42nd AIAA/ASME/ASCE/AHS/ASC Structures, Structural Dynamics, and Materials Conference, Seattle, WA, 16-19 April 2001.

10. Grosveld, Ferdinand W. and Reed Samuel A., "Sound Transmission Loss of Integrally Damped, Curved Panels," Conference Proceedings of the 1989 International Conference on Noise Control Engineering, Newport Beach, CA, December 4-6, 1989.

11. Grosveld, Ferdinand W., "Characteristics of the NASA Langley Transmission Loss Facility," NASA CR 172153, NASA Langley Research Center, Hampton, VA 23665, June 1983.

12. Grosveld, Ferdinand W., "Calibration of the Structural Acoustic Loads and Transmission (SALT) facility at NASA Langley Research Center," INTER-NOISE 99, International Congress on Noise Control Engineering, Fort Lauderdale, Florida, December 6-8, 1999.

\section{TABLES}

Table 1. Finite element modeling properties for the composite panel materials

\begin{tabular}{lcccc}
\hline $\begin{array}{c}\text { Material } \\
\text { layer }\end{array}$ & $\begin{array}{c}\text { Finite } \\
\text { elements }\end{array}$ & $\begin{array}{c}\text { Material } \\
\text { properties }\end{array}$ & $\begin{array}{c}\text { Element } \\
\text { properties }\end{array}$ & $\begin{array}{c}\text { Number of } \\
\text { elements }\end{array}$ \\
\hline $\begin{array}{l}\text { Outer } \\
\text { laminate } \\
\text { Core }\end{array}$ & CQUAD4 & $\begin{array}{c}2 D \\
\text { orthotroplc } \\
3 D\end{array}$ & PCOMP & 1764 \\
$\begin{array}{l}\text { Inner } \\
\text { laminate }\end{array}$ & CHEXA & $\begin{array}{c}\text { PSOLID } \\
\text { orthotropic } \\
2 D\end{array}$ & PCOMP & 1764 \\
\hline
\end{tabular}

Table 2. Geometric and weight properties of the panel

\begin{tabular}{llcc}
\hline & & Test article & Prediction model \\
\hline & & & \\
Radius & {$[\mathrm{in}]$} & 49.46 & 41.46 \\
Surface area & {$\left[\mathrm{in}^{2}\right]$} & 3401 & 3401 \\
Circular sector angle & {$[\mathrm{deg}]$} & 85.8 & 85.80 \\
Arc length & {$[\mathrm{in}]$} & 62.08 & 62.08 \\
Straightedge width & {$[\mathrm{in}]$} & 54.78 & 54.78 \\
Outer laminate thickness & {$[\mathrm{in}]$} & 0.0305 & 0.0305 \\
inner laminate thickness & {$[\mathrm{in}]$} & 0.0305 & 0.0305 \\
Core thickness & {$[\mathrm{in}]$} & 0.777 & 0.7770 \\
Film adhesive thickness & [in] & 0.002 & \\
Total weight & {$[$ [bs] } & 19.29 & 19.66 \\
\hline
\end{tabular}


Table 3. Comparison between modal frequencies predicted by the finite element code and the modal frequencies extracted from an experimental modal analysis for the test article with foam support (free boundary conditions).

\begin{tabular}{|c|c|c|c|c|}
\hline $\begin{array}{l}\text { Number of } \\
\text { nodal lines } \\
\text { parallel to } \\
\text { the straight } \\
\text { edge }\end{array}$ & $\begin{array}{l}\text { Number of } \\
\text { nodal lines } \\
\text { along the } \\
\text { curvature }\end{array}$ & $\begin{array}{c}\text { Finite } \\
\text { element } \\
\text { analysis } \\
\text { (free) }\end{array}$ & $\begin{array}{l}\text { Normal mode } \\
\text { analysis } \\
\text { (foam } \\
\text { support) }\end{array}$ & $\begin{array}{c}\text { Difference } \\
\text { prediction } \\
\text { versus } \\
\text { measured }\end{array}$ \\
\hline 1 & $i$ & Predicted & Measured & \\
\hline$[-]$ & {$[-]$} & {$[\mathrm{Hz}]$} & {$[\mathrm{Hz}]$} & [\%] \\
\hline 0 & 2 & 408.6 & & \\
\hline 1 & 0 & & & \\
\hline 1 & 1 & 34.2 & 34.5 & 0.9 \\
\hline 1 & 2 & 166.4 & 164.6 & -1.1 \\
\hline 1 & 3 & 294.4 & & \\
\hline 1 & 4 & 443.5 & & \\
\hline 1 & 5 & 596.8 & & \\
\hline 2 & 0 & 53.1 & 54.4 & 2.4 \\
\hline 2 & 1 & 79.2 & 77.2 & -2.6 \\
\hline 2 & 2 & 159.7 & 159.8 & 0.1 \\
\hline 2 & 3 & 294.4 & 295.3 & 0.3 \\
\hline 2 & 4 & 445.2 & & \\
\hline 2 & 5 & 597.5 & & \\
\hline 3 & 0 & 134.0 & 132.9 & -0.8 \\
\hline 3 & 1 & 156.7 & 153.6 & -2.0 \\
\hline 3 & 2 & 280.5 & 278.8 & -0.6 \\
\hline 3 & 3 & 445.3 & & \\
\hline 3 & 4 & 598.6 & & \\
\hline 4 & 0 & 233.1 & 230.0 & -1.3 \\
\hline 4 & 1 & 249.4 & 245.6 & -1.5 \\
\hline 4 & 2 & 320.3 & 318.5 & -0.6 \\
\hline 4 & 3 & 437.1 & & \\
\hline 4 & 4 & 577.3 & & \\
\hline 5 & 0 & 335.8 & 334.5 & -0.4 \\
\hline 5 & 1 & 352.0 & 350.8 & -0.3 \\
\hline 5 & 2 & 402.6 & 402.6 & 0.0 \\
\hline 5 & 3 & 492.7 & & \\
\hline 6 & 0 & 435.8 & & \\
\hline 6 & 1 & 451.8 & 451.8 & 0.0 \\
\hline 6 & 2 & 496.3 & & \\
\hline 6 & 3 & 568.7 & & \\
\hline 7 & 0 & 539.2 & & \\
\hline 7 & 1 & 550.1 & & \\
\hline 7 & 2 & 588.4 & & \\
\hline
\end{tabular}

Table 4. Comparison between modal frequencies extracted from an experimental modal analysis and the modal frequencies predicted by the finite element code for grounded spring edge conditions (elastic property value $\mathrm{EP}=7000000$ ).

\begin{tabular}{|c|c|c|c|c|c|}
\hline & & $\begin{array}{c}\text { Normal mode } \\
\text { analysis } \\
\text { (installed in } \\
\text { SALT) }\end{array}$ & $\begin{array}{l}\text { Finite } \\
\text { element } \\
\text { analysis }\end{array}$ & $\begin{array}{l}\text { Difference } \\
\text { prediction } \\
\text { versus } \\
\text { measured } \\
\end{array}$ & $\begin{array}{c}\text { Modal } \\
\text { damping }\end{array}$ \\
\hline$i$ & j & Measured & Predicted & & Measured \\
\hline$[-]$ & {$[-]$} & {$[\mathrm{Hz}]$} & {$[\mathrm{Hz}]$} & {$[\%]$} & {$[\%]$} \\
\hline 0 & 0 & & 142.6 & & \\
\hline 0 & 1 & & 281.0 & & \\
\hline 0 & 2 & & 530.2 & & \\
\hline 1 & 0 & 142.0 & 138.6 & -2.4 & 4.23 \\
\hline 1 & 1 & & 274.7 & & \\
\hline 1 & 2 & & 433.9 & & \\
\hline 1 & 3 & & 585.5 & & \\
\hline 2 & 0 & 205.6 & 201.2 & -2.1 & 2.12 \\
\hline 2 & 1 & 301.6 & 298.3 & -1.1 & 1.70 \\
\hline 2 & 2 & & 426.0 & & \\
\hline 2 & 3 & & 575.2 & & \\
\hline 3 & 0 & 299.1 & 289.9 & -3.1 & 1.64 \\
\hline 3 & 1 & 356.7 & 355.2 & -0.4 & 2.03 \\
\hline 3 & 2 & 456.5 & 465.8 & 2.0 & 3.54 \\
\hline 4 & 0 & 392.2 & 385.8 & -1.6 & 1.76 \\
\hline 4 & 1 & 439.1 & 435.1 & -0.9 & 2.33 \\
\hline 4 & 2 & 519.0 & 518.9 & 0.0 & 2.60 \\
\hline 5 & 0 & 483.9 & 482.6 & -0.3 & 2.56 \\
\hline 5 & 1 & 526.6 & 522.8 & -0.7 & 1.85 \\
\hline 5 & 2 & & 594.4 & & \\
\hline 6 & 0 & 591.3 & 578.3 & 2.2 & 1.61 \\
\hline
\end{tabular}




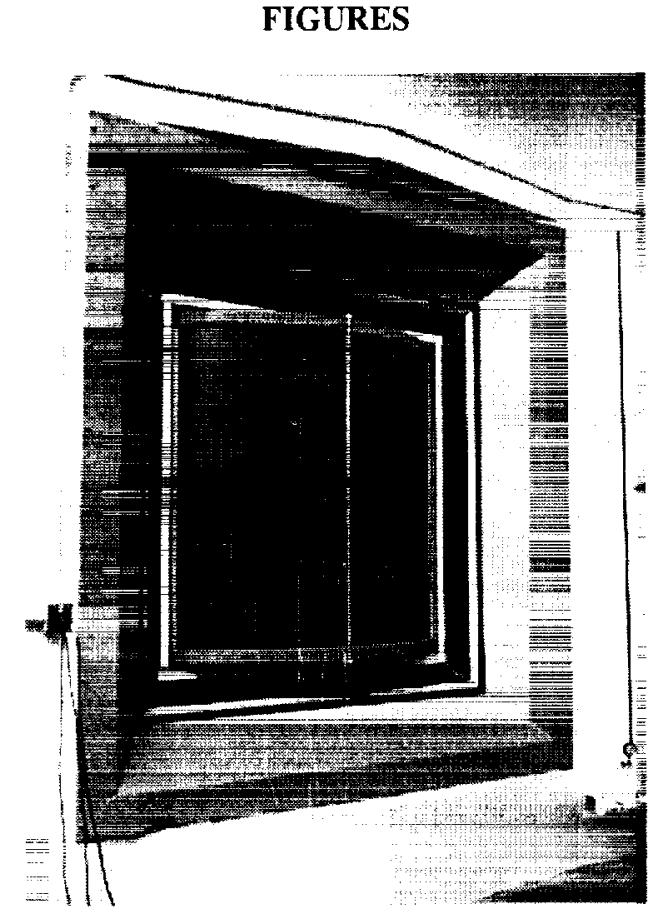

Figure I. Photograph of the curved composite honeycomb panel installed in the transmission loss window of the NASA Langley SALT (Structural Acoustic Loads and Transmission Loss) facility.
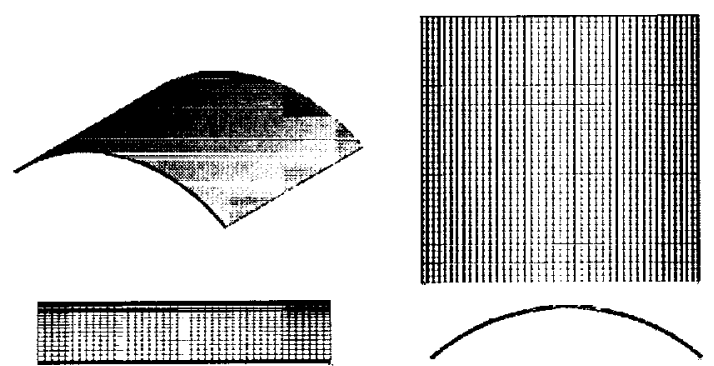

Figure 2. Quad view of the curved panel finite element model.

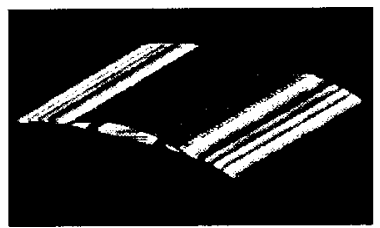

$i=2, j=0$ mode $(53.1 \mathrm{~Hz})$

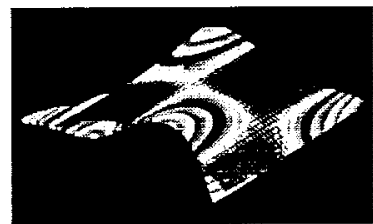

$\mathrm{i}=3, \mathrm{j}=\mathrm{l}$ mode $(\mathrm{l} 56.7 \mathrm{~Hz})$
Figure 3. Mode shapes for the curved panel finite element model with free boundary conditions.

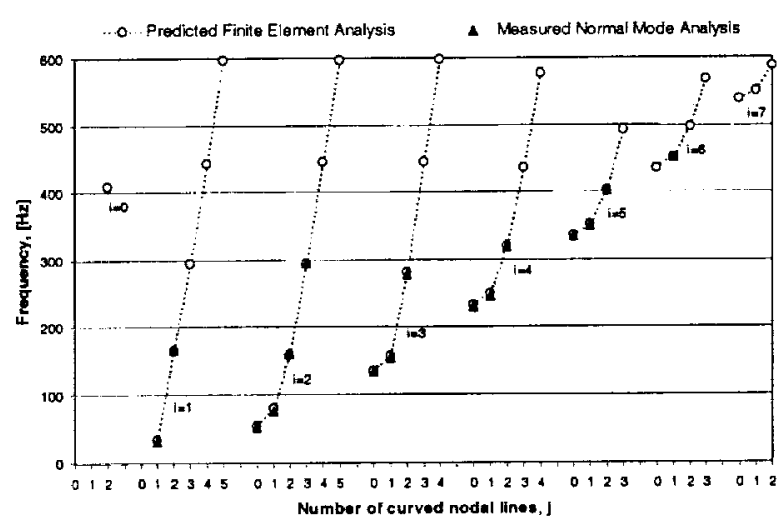

Figure 4. Comparison between predicted modal frequencies from the finite element analysis and measured modal frequencies for the curved panel with free boundary conditions (elastic support).

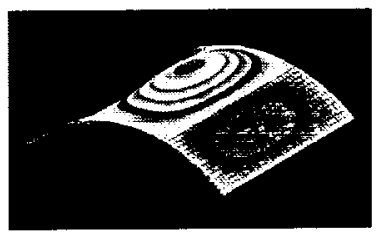

$i=2, j=0$ mode $(245.3 \mathrm{~Hz})$

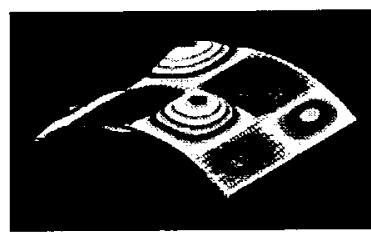

$i=3, j=1$ mode $(377.6 \mathrm{~Hz})$
Figure 5. Mode shapes for the curved panel finite element model with simply supported boundary conditions.

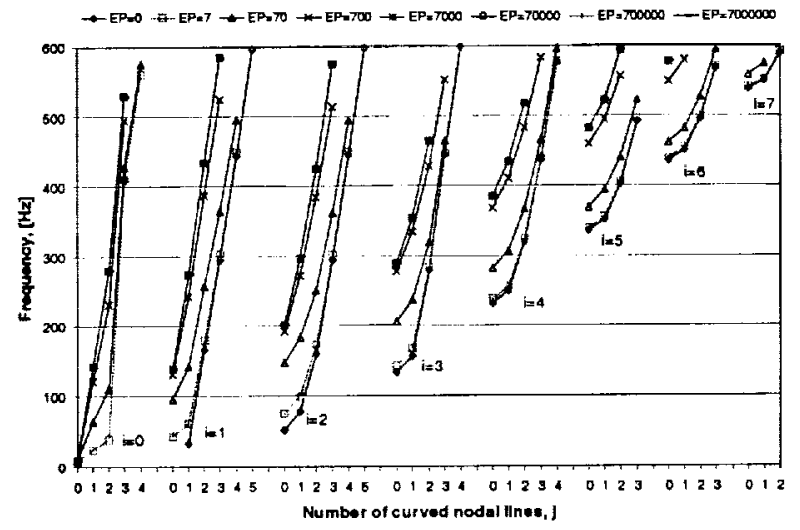

Figure 6. Modal frequencies predicted for the curved panel restricted by grounded springs in the global $x$ direction ( $i$ is the number of straight nodal lines; $j$ is the number of curved nodal lines; EP is the elastic property value). 


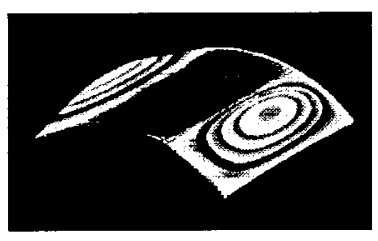

$\mathrm{i}=2, \mathrm{j}=0$ mode $(201.2 \mathrm{~Hz})$

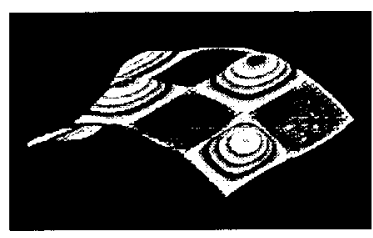

$i=3, j=1$ mode $(355.2 \mathrm{~Hz})$

Figure 7. Mode shapes for the curved panel finite element model with grounded spring boundary conditions parallel to the global $x$-axis (elastic property value $E P=7000000$ ).

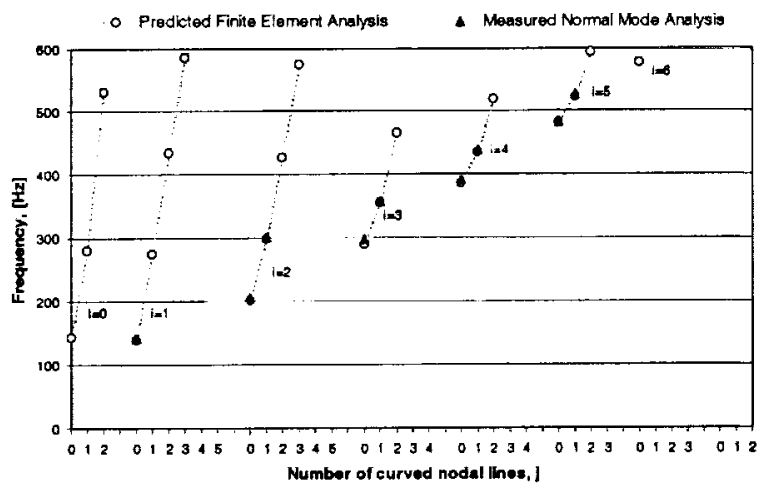

Figure 8. Comparison between the finite element predicted and the measured modal frequencies for the curved panel with boundary conditions supported by grounded springs.

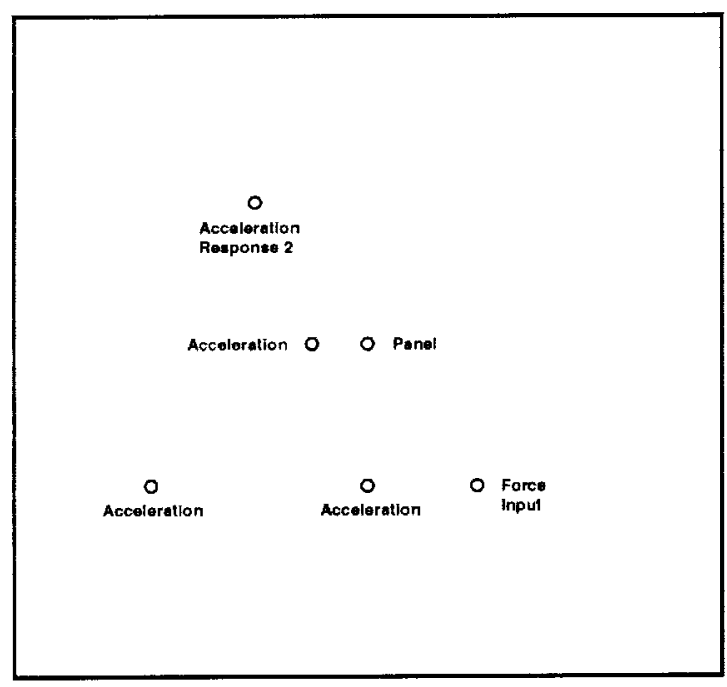

Figure 9. Top view of the curved panel showing the panel center and the locations of the force input and the four accelerometers for the experimental configuration.

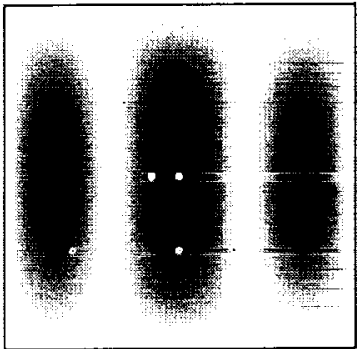

$\mathrm{i}=2, \mathrm{j}=0$ mode $(201.2 \mathrm{~Hz})$

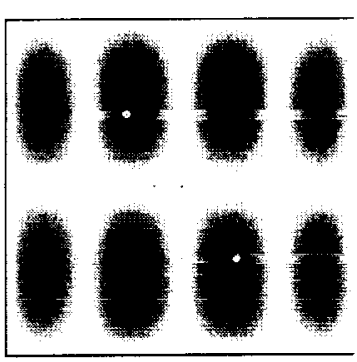

$\mathrm{i}=3, \mathrm{j}=1$ mode $(355.2 \mathrm{~Hz})$
Figure 10. Top view of two of the finite element predicted mode shape patterns showing the panel center and the locations of the force input and the four accelerometers for the experimental configuration.

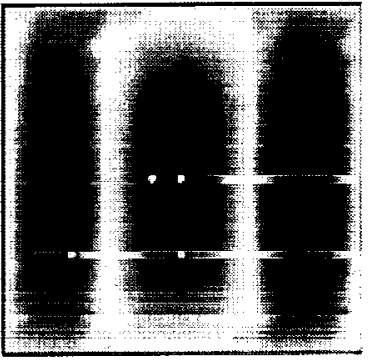

$\mathrm{i}=2, \mathrm{j}=0$ mode $(205.6 \mathrm{~Hz})$

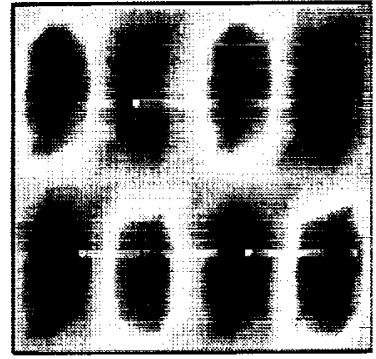

$i=3, j=1$ mode $(356.7 \mathrm{~Hz})$
Figure II. Top view of two of the measured mode shape patterns showing the panel center and the locations of the force input and the four accelerometers.

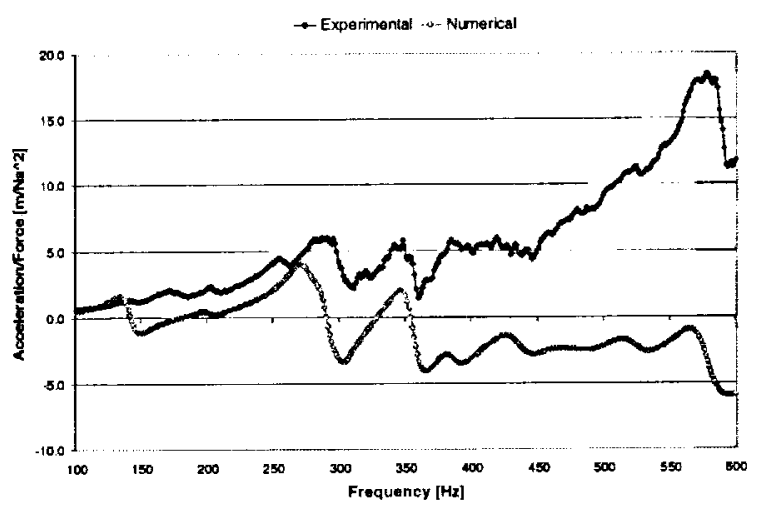

Figure 12. Measured and predicted real parts of the transfer functions between the acceleration response and the driving point force at the Force Input location including structural modes up to $600 \mathrm{~Hz}$ 


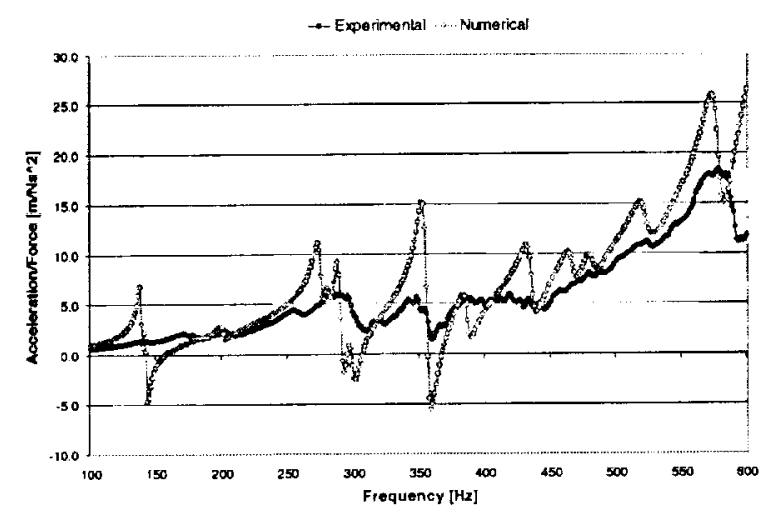

Figure 13. Measured and predicted real parts of the transfer functions between the acceleration response and the driving point force at the Force Input location using the direct approach with $1 \%$ critical damping.

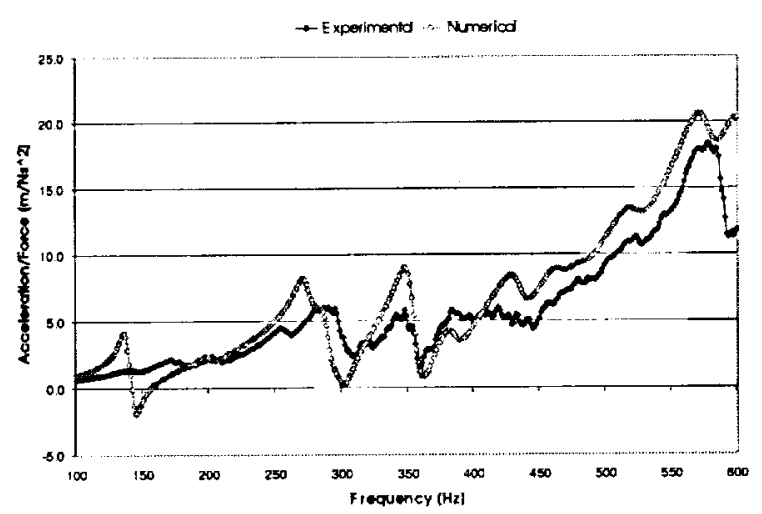

Figure 14. Measured and predicted real parts of the transfer functions between the acceleration response and the driving point force at the Force Input location using the direct approach with $1.75 \%$ critical damping.

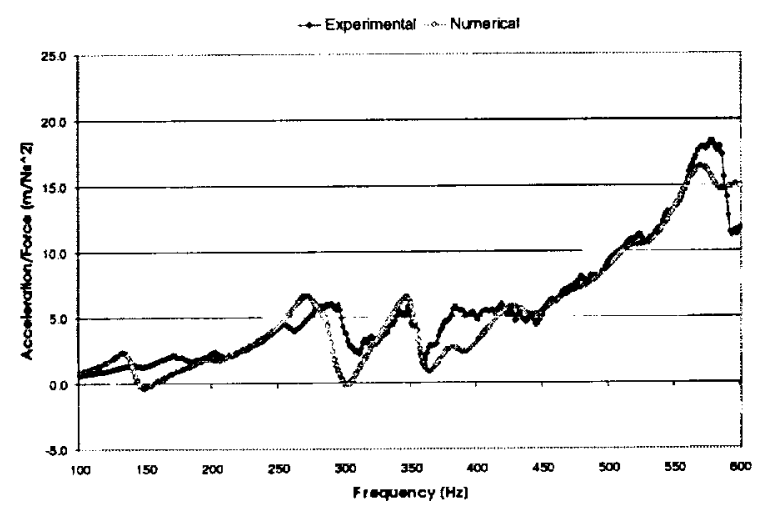

Figure 15. Measured and predicted real parts of the transfer functions between the acceleration response and the driving point force at the Force Input location including structural modes up to $3000 \mathrm{~Hz}$.

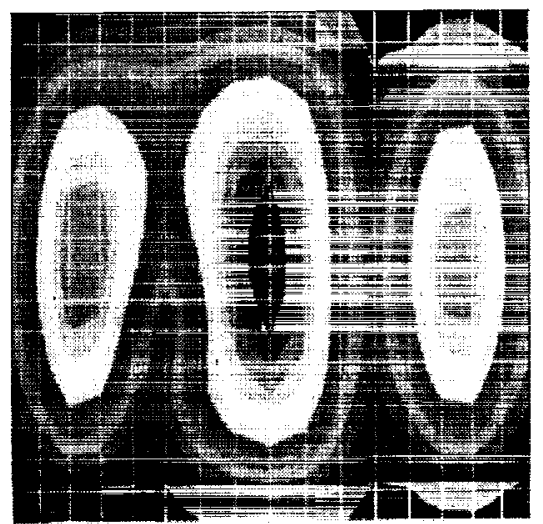

Figure 16. Finite element predicted panel surface velocity (at a frequency of $202.5 \mathrm{~Hz}$ ) interpolated and applied to the boundary element mesh.

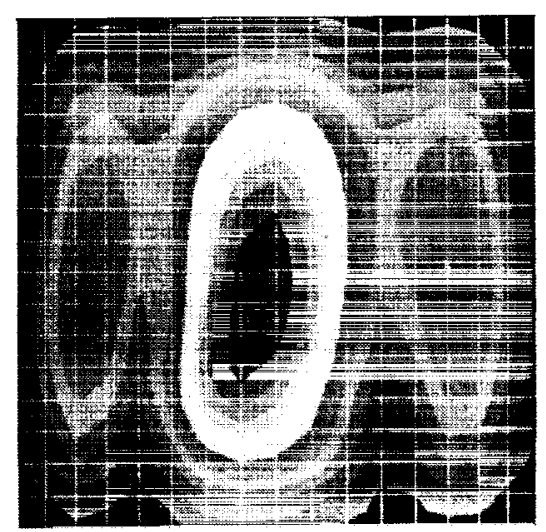

Figure 17. Measured panel surface velocity for a frequency of $202.5 \mathrm{~Hz}$ applied to the boundary element mesh

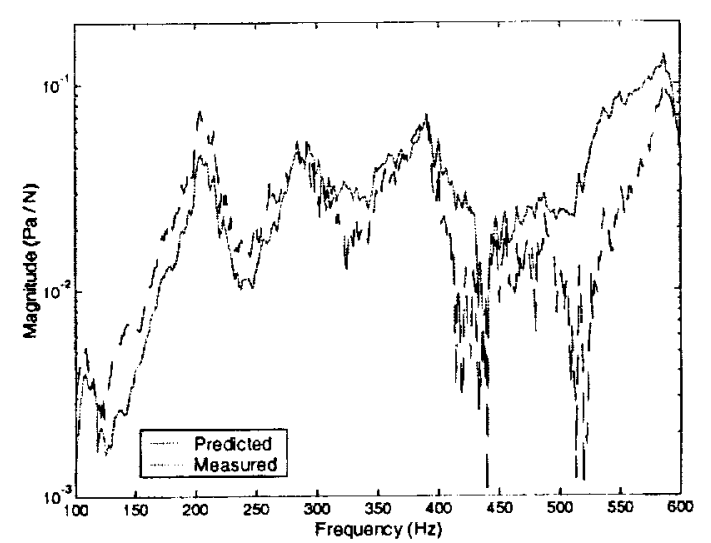

Figure 18. Measured and predicted far field sound pressure, normalized by the input force, for the measured panel surface velocity. 